\title{
Prevalence and risk factors for postpartum depressive symptoms in Argentina: a cross- sectional study
}

This article was published in the following Dove Press journal:

International Journal of Women's Health

20 November 2013

Number of times this article has been viewed

\author{
Siv Elin Mathisen' \\ Kari Glavin ${ }^{2}$ \\ Lars Lien ${ }^{3}$ \\ Per Lagerlø ${ }^{4}$
}

'Diakonhjemmet Hospital, Department of Psychiatry, Oslo, ${ }^{2}$ Diakonova University College, Department of Nursing, Oslo, ${ }^{3}$ National Center for Dual Diagnosis, Innlandet Hospital Trust and Hedmark University College, Elverum, ${ }^{4}$ Department of General Practice/ Family Medicine, Institute of Health and Society, Faculty of Medicine, University of Oslo, Oslo, Norway
Correspondence: Siv Elin Mathisen Diakonhjemmet Hospital, Pb 85 Vinderen, 0319 Oslo, Norway

Tel +4722029934/+4790882864

Email siv.mathisen@diakonsyk.no
Introduction: Postpartum depression is a prevalent disorder with negative consequences for women, infants, and the family as a whole. Most studies of this disorder have been conducted in Western countries, and studies from developing countries are few. In this paper, we report the first - as far as we are aware - study of the prevalence and risk factors associated with postpartum depressive symptoms in Argentina.

Materials and methods: The study participants were 86 women attending 6 week checkups, (range 4-12 weeks) postpartum at a private health care center in the metropolitan area of Buenos Aires. The women completed the Edinburgh Postnatal Depression Scale (EPDS) and a questionnaire collecting demographic and obstetric data. Data were described as proportions (percentages). Differences between proportions were assessed with chi-squared tests. To control for possible confounders, we fitted bivariate logistic regression models in which the dependent variable was an EPDS sum score of $<10$ versus a score of $\geq 10$.

Results: We found a high prevalence of depressive symptoms. A total of 32 women $(37.2 \%)$ had an EPDS score of $\geq 10,16(18.6 \%)$ had a score between 10 and 12, and $16(18.6 \%)$ had a score of $\geq 13$. In our sample, an EPDS score of $\geq 10$ was significantly associated with multiparity (odds ratio $[\mathrm{OR}]=3.58 ; 95 \%$ confidence interval $[\mathrm{CI}]: 1.13-11.30 ; P=0.030$ ), pregnancy complications $(\mathrm{OR}=3.40 ; 95 \% \mathrm{CI}$ : 1.03-11.26; $P=0.045)$, labor complications $(\mathrm{OR}=11.43$; 95\% CI: $1.71-76.61 ; P=0.012$ ), cesarean section (OR =4.19; 95\% CI: 1.10-16.01; $P=0.036$ ), and incomplete breast-feeding ( $\mathrm{OR}=5.00 ; 95 \% \mathrm{CI}: 1.42-17.54 ; P=0.012)$.

Conclusion: Our results indicate that postpartum depression may be prevalent in Argentina, and may be associated with incomplete breast-feeding, cesarean section, perinatal complications and multiparity. The prevalence and risk factors for postpartum depression has not been described previously and is a considerable health-related problem among women. Argentinian health professionals should be aware of the high prevalence rate and possible risk factors so that these women and families can be identified and receive adequate support and treatment.

Keywords: postpartum depression, breast-feeding, cesarean section, perinatal complications

\section{Introduction}

Postpartum depression is a prevalent disorder among women in the first year after birth and is considered a serious public health problem that is important to detect and treat. A meta-analysis of 59 studies from different countries found a mean prevalence of $13 \% .{ }^{1} \mathrm{~A}$ review of 143 studies in 40 countries, from low to high income, found large variations in prevalence, ranging from $0 \%$ to $60 \%,{ }^{2}$ and the prevalence has been shown to be higher in low- to middle-income countries. ${ }^{3}$ The prevalence of depression in the postpartum period is not higher than the prevalence of depression in other periods of a woman's life, ${ }^{4}$ but the incidence is higher in the first 3 months postpartum. ${ }^{4,5}$ Most studies have 
been conducted in industrialized countries, and there is a lack of studies from developing countries. Some studies on postpartum depression have been conducted in Latin-American countries, ${ }^{6-10}$ with the majority from Brazil and Chile. We were unable to find research studies on postpartum depression from Argentina, and the prevalence of postpartum depression in this country is largely unknown. A recent published study from Buenos Aires found a point prevalence of depression (not postpartum depression) of $20.6 \%$ among women, indicating that depression is prevalent. ${ }^{11}$

The etiology of postpartum depression remains unknown, but it is probable that several factors, including psychological, biological, and social, are involved. Among psychosocial risk factors, recent negative life events, lack of social support, and a history of depression ${ }^{12,13}$ have been strongly associated with postpartum depression. Women who suffered from depression during pregnancy were found to have a five times higher risk of developing postpartum depression, ${ }^{13}$ and women with anxiety during pregnancy were found to have a three times higher risk. ${ }^{14}$

Maternal depression has been associated with attachment difficulties in the infant ${ }^{15}$ and can have negative long-term effects on the child's cognitive, emotional, social, and behavioral development. ${ }^{16}$ Because of the negative consequences of postpartum depression, not only for women but also for their infant and family as a whole, it is important to detect and treat this disabling disorder. However, in spite of increasing evidence that postpartum depression can be effectively treated and possibly prevented, it often goes undetected and untreated in many women. ${ }^{17}$ A study of primary health care in Bolton, England, found that health care personnel detected postpartum depression in fewer than half of those women with it. ${ }^{18}$ Improved mental health is closely linked to the fifth Millennium Development Goal to improve maternal health. ${ }^{19}$

Thus, the aim of our study was to describe the prevalence of postpartum depressive symptoms and show possible associations with potential risk factors and frequency of breast-feeding in a population of postpartum women at a health care clinic in Buenos Aires, Argentina.

\section{Materials and methods Setting}

This study is a result of research collaboration between the University of Oslo and Universidad de Buenos Aires focusing on mother/infant health in primary care. The study was conducted at a private well-baby clinic in the metropolitan area of Buenos Aires that has established ties with the Universidad de Buenos Aires, participating in the education of medical students. The well-baby clinic is a private clinic serving a middle-class population with health insurance from its workers' union, Obras Sociales.

\section{Study population}

Women attending their normal 6-week postpartum check-up at the Sanatorio Modelo de Caseros Well-Baby Clinic in Provincia de Buenos Aires, Argentina, were invited to participate. Inclusion criteria were women who had given birth to a live infant and were able to speak and write Spanish fluently. Women who could not speak and write Spanish fluently were excluded from the study.

\section{Recruitment of participants}

A health secretary at the Sanatorio Modelo de Caseros WellBaby Clinic distributed written information about the study to all women who attended the clinic for their normal 6-week postpartum care visit. The women were recruited consecutively from October 2011 to November 2012. Women who agreed to participate in the study signed a written informed consent form designed to meet the requirements of the Norwegian Regional Ethics Committee. The health secretary then distributed the Edinburgh Postnatal Depression Scale (EPDS) and the questionnaire, which the women completed anonymously at the clinic immediately before or after their scheduled check. (The scale and questionnaire are described in the "Instruments" section.) The women then returned their completed questionnaire in a sealed envelope to the health secretary. The questionnaires were stored in a secure place separate from the signed consent forms.

\section{Instruments EPDS}

The EPDS was developed by Cox et $\mathrm{al}^{20}$ to detect depressive symptoms among women who had recently given birth. The EPDS questionnaire consists of ten questions for self-completion. Each question has four response options, and is rated on a four-point scale from 0 to 3 , giving a total score between 0 and 30 . Higher scores indicate more severe symptoms. The scale shows the intensity in depressive symptoms present during the last 7 days. The instrument has been used in clinical settings and epidemiological studies and is generally well accepted by women. The EPDS used in our study was validated in Spanish. ${ }^{21-23}$

\section{Questionnaire}

We designed a questionnaire focusing on sociodemographics and known psychosocial risk factors for postpartum depression. The questions concerned: satisfaction 
with partner (on a four-point scale from "very satisfied" to "not satisfied"); support from partner and others (on a fourpoint scale from "very satisfied" to "not satisfied"); history of mental health problems, including mental health problems during pregnancy; current, past, and prenatal treatment for mental health disorders; use of alcohol, illegal drugs, or tobacco ("yes" or "no"); negative life events over the last year ("yes" or "no," with the opportunity to specify in their own words); somatic illness; whether their pregnancy was planned; morning sickness; complications during pregnancy and birth (with the opportunity to specify the type of complications); cesarean section, including whether a cesarean section was planned and the reason for performing a cesarean section; degree of breast-feeding (three options: complete, partial or none); and motivation for breast-feeding before birth and at the time of the study.

\section{Ethics}

The study was conducted in accordance with the Helsinki Declaration on Human Rights. The study was approved by the Norwegian Regional Ethics Committee (reference no 2011/1073-6) and approved by the Director of Sanatorio Modelo de Caseros. Each individual participated voluntarily, and had the opportunity to withdraw from the study without any consequences for the health care service provided to them.

\section{Statistical procedures}

We established an electronic database using EpiData version 3.1 (The EpiData Association, Odense, Denmark). We then transferred the data into SPSS software (version 20; IBM Corporation, Armonk, NY, USA) by performing double entry to ensure the data transfer was correct.

Data were described as proportions (percentages). Differences between proportions were assessed with twotailed unadjusted chi-square tests. To control for possible confounders, we fitted bivariate logistic regression models, where the dependent variable was an EPDS sum score of $<10$ versus $\geq 10$. This cutoff point was selected to ensure a comparable number of participants in each group, and to correspond with a cutoff point frequently used to identify less severe depression. In designing the model, we included independent variables that correlated with the dependent variable with a $P$-value $<0.1$ using Pearson's correlation. Among the independent variables that showed a statistically significant correlation with each other, we chose the one giving the highest $R$-squared value. The results are presented as odds ratios, with $95 \%$ confidence intervals. Values were missing for $<5 \%$ of all questions. $P$-values $<0.05$ were considered statistically significant, and all tests were twosided. All analyses were conducted using the SPSS software mentioned earlier.

\section{Results}

Questionnaires were completed by 86 women. The mean age of participants was 28.3 years (range 17-45 years). Of the participants, 81 were Argentinean (94.2\%) and five (5.8\%) came from neighboring countries (Peru and Paraguay). Almost three-quarters $(62 ; 72.1 \%)$ of the women's infants were 6 weeks old (range 4-12 weeks). A total of 36 women (41.9\%) fully breast-fed, 40 (46.5\%) partially breast-fed, and nine $(10.5 \%)$ formula-fed their infants. The last two categories, partial breast-feeding and formula feeding, were grouped together in our analysis as the category "incomplete breast-feeding."

We found no significant differences in terms of the women's age, civil status, level of education, work status, housing conditions, economy, smoking, whether the pregnancy was planned, motivation for breast-feeding, or the sex of their infant between women who scored $<10$ and those who scored $\geq 10$ on the EPDS. However, we found a significantly higher frequency of incomplete breast-feeding, multiparity, and complications during pregnancy among those with an EPDS score $\geq 10$ (Table 1).

Of our sample of 86 women, 27 (31.4\%) had an EPDS score of $\leq 4$ (indicating no depression), 27 (31.4\%) had an EPDS score of between five and nine (indicating some depressive symptoms), 16 (18.6\%) had a score between ten and 12 (indicating mild depression), and 16 (18.6\%) women had an EPDS score of $\geq 13$ (indicating clinical depression). Only three women (3.5\%) in the sample had a history of mental health problems, and only one (1.2\%) had received treatment for mental health problems in the past. In spite of a high prevalence of high EPDS scores, none of the women was currently receiving professional treatment; however, only $58(67.4 \%)$ responded to this last question. One woman $(1.2 \%)$ had used illegal drugs during pregnancy, five $(5.8 \%)$ had used alcohol, and seven $(8.7 \%)$ had smoked cigarettes during pregnancy. We observed a high number of cesarean sections performed in our sample $(57 ; 66.3 \%)$. A total of 23 women (26.7\%) experienced complications during pregnancy. The types of complications mentioned were gestational diabetes, hypertension, renal insufficiency, asthma, cholestasis, anemia, premature rupture of the amniotic sac, hemorrhages, threatened abortion, and cerclage. Birth complications were experienced by seven women 
Table I Characteristics of mothers with Edinburgh Postpartum Depression Scale (EPDS) scores $\leq 9$ compared with those with scores $\geq 10$

\begin{tabular}{|c|c|c|c|}
\hline Characteristic & $\begin{array}{l}\text { EPDS } \\
\text { score } \leq 9, \\
\mathrm{~N}=54(\%)\end{array}$ & $\begin{array}{l}\text { EPDS } \\
\text { score } \geq 10, \\
\mathrm{~N}=32(\%)\end{array}$ & $P$-value \\
\hline \multicolumn{4}{|l|}{ Age, years } \\
\hline $17-25$ & $23(42.6)$ & $9(28.1)$ & 0.180 \\
\hline $26-35$ & $26(48.1)$ & $18(56.3)$ & 0.468 \\
\hline$\geq 36$ & $5(9.3)$ & $5(15.6)$ & 0.373 \\
\hline \multicolumn{4}{|l|}{ Child } \\
\hline Male & $32(59.3)$ & $13(40.6)$ & 0.094 \\
\hline First child & $34(63.0)$ & $13(40.6)$ & $0.044^{*}$ \\
\hline \multicolumn{4}{|l|}{ Civil status } \\
\hline Married & $15(27.8)$ & $7(21.9)$ & 0.544 \\
\hline Living with a partner & $34(63.0)$ & $21(65.6)$ & 0.804 \\
\hline Single & $5(9.3)$ & $4(12.5)$ & 0.635 \\
\hline Smoking & $4(7.4)$ & $3(9.4)$ & 0.747 \\
\hline \multicolumn{4}{|l|}{ Education } \\
\hline Primary school & $9(16.7)$ & $4(12.5)$ & 0.602 \\
\hline Junior High School & $30(55.6)$ & $19(59.4)$ & 0.730 \\
\hline High School or University & $15(27.8)$ & $8(25.0)$ & 0.779 \\
\hline \multicolumn{4}{|l|}{ Work } \\
\hline Outside home & $26(48.1)$ & $16(50.0)$ & 0.868 \\
\hline In the home & $20(37.0)$ & II (34.4) & 0.804 \\
\hline Other & $8(14.8)$ & $3(9.4)$ & 0.465 \\
\hline \multicolumn{4}{|l|}{ Housing and economy } \\
\hline \multicolumn{4}{|l|}{ Ownership } \\
\hline Own the house & $18(33.3)$ & $14(43.8)$ & 0.334 \\
\hline Rent the house & $27(50.0)$ & $13(40.6)$ & 0.400 \\
\hline Not specified & $9(16.7)$ & $4(12.5)$ & 0.602 \\
\hline \multicolumn{4}{|l|}{ No of rooms } \\
\hline 2 or less rooms & $30(55.6)$ & $17(53.1)$ & 0.827 \\
\hline 3 or more rooms & $22(40.7)$ & $14(43.8)$ & 0.785 \\
\hline \multicolumn{4}{|l|}{ Living with others } \\
\hline Living with parents & II (20.4) & $9(28.1)$ & 0.411 \\
\hline $\begin{array}{l}\text { Living with other } \\
\text { family members }\end{array}$ & $10(18.5)$ & $6(18.8)$ & 0.979 \\
\hline \multicolumn{4}{|l|}{ Economy } \\
\hline $\begin{array}{l}\text { Difficulties paying } \\
\text { monthly expenses }\end{array}$ & $6(11.1)$ & $6(18.8)$ & 0.323 \\
\hline \multicolumn{4}{|l|}{ Pregnancy and labor } \\
\hline Pregnancy was planned & $30(55.6)$ & $13(40.6)$ & 0.181 \\
\hline $\begin{array}{l}\text { No complications during } \\
\text { pregnancy }\end{array}$ & $43(79.6)$ & $19(59.4)$ & $0.043 *$ \\
\hline $\begin{array}{l}\text { Cesarean section was } \\
\text { preplanned }\end{array}$ & 14 (25.9) & $12(37.5)$ & 0.256 \\
\hline $\begin{array}{l}\text { Cesarean section was } \\
\text { performed }\end{array}$ & $32(59.3)$ & $25(78.1)$ & 0.074 \\
\hline $\begin{array}{l}\text { No complications during } \\
\text { labor }\end{array}$ & $48(88.9)$ & $25(78.1)$ & 0.178 \\
\hline \multicolumn{4}{|l|}{ Breast-feeding } \\
\hline Strongly motivated & $50(92.6)$ & $25(78.1)$ & 0.052 \\
\hline $\begin{array}{l}\text { Complete breast-feeding } \\
\text { accomplished }\end{array}$ & $28(51.9)$ & $8(25.0)$ & $0.015^{*}$ \\
\hline
\end{tabular}

Notes: aComplete breast-feeding includes all women who completely breast-fed, while incomplete breast-feeding includes the women who partially breast-fed or bottle-fed; $* P<0.05$, two-tailed unadjusted chi-square test.

Abbreviations: EPDS, Edinburgh Postpartum Depression Scale.
(8.1\%). The types of complications mentioned were meconium aspiration, placental insufficiency, baby lodging in the birth canal, narrow birth canal, nuchal umbilical cord, macrosomia, hemorrhages, prolapse, and anxiety attacks.

The independent variables were primipara versus multipara, complications versus lack of complications during pregnancy and birth, cesarean section versus no cesarean section, and breast-feeding (complete versus incomplete). The results from the bivariate regression analysis are summarized in Table 2, and show an increased risk of scoring $\geq 10$ on the EPDS for those who gave positive statements on five independent variables: multiparity, pregnancy complications, birth complications, cesarean section, and incomplete breast-feeding. The model explained $28.4 \%$ of the variance of the dependent variable (Cox and Snell's $R$-square).

\section{Discussion}

In our sample of postpartum Argentinean women, we found a relatively high prevalence of depressive symptoms compared with in women of Western, especially Nordic, countries. The prevalence is similar to high rates found in other LatinAmerican countries like Chile and Mexico. ${ }^{24,25}$ We were not able to detect major differences in the women's age, civil status, education, or economy between those with high EPDS scores of $\geq 10$, and those with lower EPDS scores. A high frequency of depressive symptoms (EPDS $\geq 10$ ) was associated with multiparity, experiencing complications during pregnancy and birth, cesarean section, and incomplete breast-feeding.

\section{Multiparity}

Having more children was associated with higher EPDS scores in our sample, and may reflect a higher care burden and psychosocial stress. Studies have shown different results

Table 2 Bivariate logistic regression model with the dependent variable Edinburgh Postpartum Depression Scale (EPDS) scores of $\leq 9$ versus scores of $\geq 10$

\begin{tabular}{llll}
\hline Variable & OR & $\mathbf{9 5 \% ~ C l ~}$ & P-value \\
\hline Parity (ref first child) & 3.580 & $1.13-11.30$ & 0.030 \\
Complications during pregnancy & 3.400 & $1.03-11.26$ & 0.045 \\
(ref no) & & & \\
Complications during labor (ref no) & 11.430 & $1.71-76.61$ & 0.012 \\
Cesarean section (ref no) & 4.190 & $1.10-16.01$ & 0.036 \\
Breast-feeding (ref complete) & 4.995 & $1.42-17.54$ & 0.012 \\
\hline
\end{tabular}

Notes: Independent variables were parity, whether the pregnancy was planned, any occurrence of complications during pregnancy or during birth, whether cesarean section was performed, and whether the child was fully breast-fed at the time of the EPDS screening.

Abbreviations: $\mathrm{Cl}$, confidence interval; no, number; OR, odds ratio; ref, reference. 
when it comes to parity and postpartum depression; some have found a higher prevalence among multiparous women, ${ }^{26,27}$ while others have found that primiparae are more at risk. ${ }^{28}$

\section{Cesarean section}

We found a high frequency $(66.3 \%)$ of cesarean sections in our sample. These women had a significantly higher risk of expressing more depressive symptoms than those giving birth vaginally. However, we did not detect associations between planned versus unplanned cesarean sections. Our findings are in accordance with a Chinese prospective study from 2011 in a population with a high frequency of cesarean sections $(77.7 \%) .{ }^{29}$ In that study, the postpartum rate of depression was $21.7 \%$ in women who had a cesarean delivery and $10.7 \%$ in women who delivered vaginally. ${ }^{29}$ Similarly, a Canadian prospective cohort study of 2,560 women found cesarean sections to be associated with postpartum depression in Canadian-born women, but not in women born outside Canada. ${ }^{30}$ In a review of 24 studies by Carter et al, ${ }^{31}$ five studies showed significant adverse associations between postpartum depression and cesarean sections, 15 showed no significant association, and four found mixed results. The authors of the review discussed whether cesarean section may be a weak risk factor and if different aspects of the procedure, such as whether the cesarean section was planned, whether it was an emergency situation, and the degree of control the woman experienced during the procedure, may be of importance. They concluded that the largest and most methodologically sound studies have not been able to show an association. ${ }^{31}$

\section{Perinatal complications}

Complications during pregnancy and birth were significantly associated with postpartum depressive symptoms in our Argentinean sample. These are similar to the findings of a large Dutch study of 4,941 women, in which preeclampsia, hospitalization, and emergency cesarean section, a medically indicated delivery provided by an obstetrician, and hospital admission of the infant were significantly associated with postpartum depression. In that study, the risk of postpartum depression increased with an increasing number of complications..$^{32} \mathrm{~A}$ Japanese study of 627 women found high EPDS scores were significantly associated with premature delivery and difficult labor. ${ }^{33}$

\section{Breast-feeding}

The advantages of breast-feeding are recognized worldwide, and include benefits for both the infant and the mother. ${ }^{34}$ According to WHO on infant and young children feeding
$54.9 \%$ of a sample Argentinean mothers continued breastfeeding after 1 year (2004-2005). ${ }^{35}$ In our sample, 36 (41.9\%) women fully breast-fed their children at the time of the study. A qualitative systematic review of 49 studies showed that women who had depressive symptoms early in the postpartum period had an increased risk of a reduced duration of breast-feeding, increased difficulties with breast-feeding, and reduced selfefficacy. The study indicated that depressed mothers appeared to initiate breast-feeding to a lesser degree than mothers without depressive symptoms. ${ }^{36}$ A large Norwegian cohort study of 42,225 women identified breast-feeding cessation as a risk factor for increased anxiety and depression. Further, women who experienced anxiety and depression during pregnancy and who stopped breast-feeding were at increased risk of postpartum anxiety and depression. ${ }^{37}$ In a cross-sectional study of 89 Brazilian women, women who partially breast-fed were found to have higher EPDS scores than women who fully breast-fed, and the study concluded that women with depressive symptoms had impaired self-efficacy. ${ }^{38}$

Of concern is that none of the women in our sample reported that she received professional help at the time of the study, although Argentina has the highest ratio of psychologists per capita and is known for its focus on mental well-being. This may indicate that the knowledge and focus on postpartum depression are insufficient.

\section{Strengths and weaknesses}

The findings of the present study should be interpreted with caution, considering the small sample size and wide confidence intervals. Further, our sample was a selected group of mothers representing mainly middle-class women. The participants had a low prevalence of prior psychiatric history, and virtually no drug or alcohol problems. Although the women were recruited consecutively, recording of nonresponders was not performed. Reports from the Well-Baby Clinic indicate that the number of nonresponders was low, but selection bias toward women of higher socioeconomic status cannot be excluded. Finally, it is important to emphasize that the EPDS is a screening instrument that indicates depressive symptoms in the last 7 days, based on self-report; it is not an instrument designed to yield a diagnosis of depression.

\section{Conclusion}

We found a high prevalence of depressive symptoms in our sample of Argentinean postpartum women. Depressive symptoms were associated with multiparity, perinatal complications, cesarean section, and incomplete breast-feeding. Our results 
indicate that postpartum depression might be prevalent in Argentina. This does not seem to be fully recognized and may be a considerable health care problem that is important to detect and treat. As such, Argentinean health professionals should be aware of the high prevalence rate and possible risk factors, so that these women can be identified and both them and their families can receive adequate support and treatment. Further prevalence studies should be conducted in various settings in Argentina, and should include larger samples of women and be conducted in resource-poor settings. Studies should also be undertaken to validate the EPDS and determine appropriate cutoff values.

\section{Acknowledgments}

The authors wish to thank Carlos Needleman, professor in pediatrics at the Universidad de Buenos Aires and Karoline Sunnarvik-Ween, Norwegian medical exchange student at the Universidad de Buenos Aires. They also wish to thank Ana María González, Florencia Barril, Elisabeth Bellanti, Celeste Celano, Luis Falcone, Gabriel Ferreyra, Diego Fidanza, Mariel Fernández, María García, and Natalia Trípoli, medical doctors at Sanatorio Modelo Caseros; the health secretaries at Sanatorio Modelo Caseros for assisting in collection of data; and Hiroko Solvang, statistician at the University of Oslo, for assisting in statistical analysis.

\section{Disclosure}

The authors report no conflicts of interest in this work.

\section{References}

1. O'Hara MW, Swain AM. Rates and risks of postpartum depression: a meta-analysis. Int Rev Psychiatry. 1996;8(1):37-54.

2. Halbreich U, Karkun S. Cross-cultural and social diversity of prevalence of postpartum depression and depressive symptoms. J Affect Disord. 2006;91(2-3):97-111.

3. Almond P. Postnatal depression: a global public health perspective. Perspect Public Health. 2009;129(5):221-227.

4. Cooper PJ, Campbell EA, Day A, Kennerley H, Bond A. Non-psychotic psychiatric disorder after childbirth. A prospective study of prevalence, incidence, course and nature. Br J Psychiatry. 1998;152:799-806.

5. Munk-Olsen T, Laursen TM, Pedersen CB, Mors O, Mortensen PB. New parents and mental disorders: a population-based register study. JAMA. 2006;296(21):2582-2589.

6. Wolf AW, De Andraca I, Lozoff B. Maternal depression in three Latin American samples. Soc Psychiatr Epidemiol. 2002;37(4):169-176.

7. Quelopana AM, Champion JD, Reyes-Rubilar T. Factors associated with postpartum depression in Chilean women. Health Care Woman Int. 2011;32(10):939-949.

8. Rojas G, Fritsch R, Solis J, et al. Treatment of postnatal depression in lowincome mothers in primary-care clinics in Santiago, Chile: a randomised controlled trial. Lancet. 2007;370(9599):1629-1637.

9. Melo EF Jr, Cecatti JG, Pacagnella RC, Leite DF, Vulcani DE, Makuch MY. The prevalence of perinatal depression and its associated factors in two different settings in Brazil. J Affect Disord. 2012;136(3):1204-1208.
10. Lobato G, Moraes CL, Dias AS, Reichenheim ME. Postpartum depression according to time frames and sub-groups: a survey in primary health care settings in Rio de Janeiro, Brazil. Arch Womens Ment Health. 2011;14(3):187-193.

11. Leiderman EA, Lolich M, Vázquez GH, Baldessarini RJ. Depression: point-prevalence and sociodemographic correlates in a Buenos Aires community sample. J Affect Disord. 2012;136(3):1154-1158.

12. Beck CT. Predictors of postpartum depression: an update. Nurs Res. 2001;50(5):275-285.

13. Robertson E, Grace S, Wallington T, Stewart DE. Antenatal risk factors for postpartum depression: a synthesis of recent literature. Gen Hosp Psychiatry. 2004;26(4):289-295.

14. Milgrom J, Gemmill AW, Bilszta JL, et al. Antenatal risk factors for postnatal depression: a large prospective study. J Affect Disord. 2008; 108(1-2):147-157.

15. Campbell SB, Brownell CA, Hungerford A, Spieker SI, Mohan R, Blessing JS. The course of maternal depressive symptoms and maternal sensitivity as predictors of attachment security at 36 months. Dev Psychopathol. 2004;16(2):231-252.

16. Grace SL, Evindar A, Stewart DE. The effect of postpartum depression on child cognitive development and behavior: a review and critical analysis of the literature. Arch Womens Ment Health. 2003;6(4) 263-274.

17. Dennis CL. Preventing and treating postnatal depression. BMJ. 2009;15;338:a2975.

18. Hearn G, Iliff A, Jones I, et al. Postnatal depression in the community. Br J Gen Pract. 1998;48(428):1064-2066.

19. Fisher JR, de Mello MC, Izutsu T, Tran T. The Ha Noi Expert Statement: recognition of maternal mental health in resource-constrained settings is essential for achieving the Millennium Development Goals. Int $J$ Ment Health Syst. 2011;5(1):2.

20. Cox JL, Holden JM, Sagovsky R. Detection of postnatal depression. Development of the 10-item Edinburgh Postnatal Depression Scale. $\mathrm{Br}$ J Psychiatry. 1987;150:782-786.

21. Vega-Dienstmaier JM, Mazzotti Suárez G, Campos Sánchez M. [Validation of a Spanish version of the Edinburgh Postnatal Depression Scale.] Actas Esp Psiquiatr. 2002;30(2):106-111. Spanish.

22. Jadresic E, Araya R, Jara C. Validation of the Edinburgh Postnatal Depression Scale (EPDS) in Chilean postpartum women. J Psychosom Obstet Gynecol. 1995;16(4):187-191.

23. Alvarado-Esquivel C, Sifuentes-Alvarez A, Salas-Martinez C, MartínezGarcía S. Validation of the Edinburgh Postpartum Depression Scale in a population of puerperal women in Mexico. Clin Pract Epidemiol Ment Health. 2006;2:33.

24. Jadresic EM, Araya RB. Prevalencia de dépresion postparto y factores asociados en Santiago, Chile [Prevalence of postpartum depression and associated factors in Santiago, Chile]. Rev Med Chil. 1995;123(6): 694-699. Spanish.

25. Alvarado-Esquivel C, Sifuentes-Alvarez A, Estrada-Martínez S, et al. Prevalencia de dépresion postnatal en mujeres atendidas en hospitales públicos de Durango, Mexico [Prevalence of postnatal depression in women attending public hospitals in Durango, Mexico]. Gac Méd Méx. 2010;146(1):1-9.

26. Mayberry LJ, Horowitz JA, Declercq E. Depression symptom prevalence and demographic risk factors among US women during the first 2 years postpartum. J Obstet Gynecol Neonatal Nurs. 2007;36(6): 542-549.

27. Righetti-Veltema M, Conne-Perréard E, Bousquet A, Manzano J. Risk factors and predictive signs of postpartum depression. J Affect Disord. 1998;49(3):167-180

28. Kheirabadi GR, Maracy MR, Barekatain M, et al. Risk factors of postpartum depression in rural areas of Isfahan Province, Iran. Arch Iran Med. 2009;12(5):461-467.

29. Xie RH, Lei J, Wang S, Xie H, Walker M, Wen SW. Cesarean section and postpartum depression in a cohort of Chinese women with a high cesarean delivery rate. $J$ Womens Health (Larchmt). 2011;20(12): 1881-1886. 
30. Sword W, Landy CK, Thabane L, et al. Is mode of delivery associated with postpartum depression at 6 weeks: a prospective cohort study. BJOG. 2011;118(8):966-977.

31. Carter FA, Frampton CM, Mulder RT. Cesarean section and postpartum depression: a review of the evidence examining the link. Psychosom Med. 2006;68(2):321-330.

32. Blom EA, Jansen PW, Verhulst FC, et al. Perinatal complications increase the risk of postpartum depression. The Generation R Study. BJOG. 2010;117(11):1390-1398.

33. Tamaki R, Murata M, Okano T. Risk factors for postpartum depression in Japan. Psychiatry Clin Neurosci. 1997;51(3):93-98.

34. Hoddinott P, Tappin D, Wright C. Breast feeding. BMJ. 2008; 336(7649):881-887.
35. World Health Organization [WHO]. WHO Global Data Bank on Breastfeeding and Complementary Feeding [database on the Internet]. Geneva: WHO; nd. www.who/int/nutrition/databases/infantfeeding/en. Accessed October 20, 2013.

36. Dennis CL, McQueen K. The relationship between infant-feeding outcomes and postpartum depression: a qualitative systematic review. Pediatrics. 2009;123(4):736-751.

37. Ystrom E. Breastfeeding cessation and symptoms of anxiety and depression: a longitudinal cohort study. BMC Pregnancy Childbirth. 2012;12:36.

38. Zubaran C, Foresti K. The correlation between breastfeeding selfefficacy and maternal postpartum depression in southern Brazil. Sex Reprod Health. 2013;4(1):9-15.
International Journal of Women's Health

\section{Publish your work in this journal}

The International Journal of Women's Health is an international, peerreviewed open-access journal publishing original research, reports, editorials, reviews and commentaries on all aspects of women's healthcare including gynecology, obstetrics, and breast cancer. The manuscript management system is completely online and includes

\section{Dovepress}

a very quick and fair peer-review system, which is all easy to use. Visit http://www.dovepress.com/testimonials.php to read real quotes from published authors.

\footnotetext{
Submit your manuscript here: http://www.dovepress.com/international-journal-of-womens-health-journal
} 